\title{
The Burgess Shale animal Oesia is not a chaetognath: A reply to Szaniawski (2005)
}

Simon Conway Morris

Acta Palaeontologica Polonica 54 (1), 2009: 175-179 doi:http://dx.doi.org/10.4202/app.2009.0120

The Middle Cambrian Oesia disjuncta, a monospecific genus, is known only from the celebrated Burgess Shale of British Columbia. It has been re-interpreted by Szaniawski (Acta Palaeontologica Polonica 50:1-8; 2005) as a chaetognath, a distinctive phylum whose exact position in the protostomes is still controversial. Unequivocal chaetognaths, that have no similarity to Oesia, are already known to occur in the Chengjiang Lagerstätte (Lower Cambrian, S.W. China), and here I describe the first example of a chaetognath from the Burgess Shale itself. Comparisons between Oesia and chaetognaths fail to find any significant homologies. Whilst the phyletic position of Oesia is very uncertain, a place in the hemichordates may be worth exploring.

Simon Conway Morris [sc113@esc.cam.ac.uk], Department of Earth Sciences, University of Cambridge, Downing Street, Cambridge CB2 3EQ, England

This is an open-access article distributed under the terms of the Creative Commons Attribution License (for details please see creativecommons.org), which permits unrestricted use, distribution, and reproduction in any medium, provided the original author and source are credited. 